\title{
Innovative E-Therapy Service in Higher Education: Mobile Application Design
}

\author{
https://doi.org/10.3991/ijim.v11i4.6734 \\ Miftachul Huda, Kamarul Azmi Jasmi, Mohd Ismail Mustari, Bushrah Basiron, \\ Ahmad Kilani Mohamed, Wan Hassan Wan Embong, Jimaain Safar \\ Universiti Teknologi Malaysia, Johor, Malaysia \\ halimelhuda@gmail.com
}

\begin{abstract}
Cyber counselling or e-therapy has widely been adopted as the new approach to give an insightful guidance into the clients. In higher education (HE) level, this initiative seems to have rarely been involved due to some technical requirements and preparations. This paper aims to present the approach of e-therapy using mobile application design. The finding illustrates that promoting this model application can theoretically assist the transmission process of counselling in the academic circumstance where both students and advisors may have a continuous engagement with more convenient quality in solving the issues surrounding the academic purposes. The attainment of this paper is expected to contribute in enabling the process of academic counselling in the context of higher education (HE). Strengthening practical and relational value maintaining connection to facilitate the sensitive issues disclosure is expected to help students solve their academic issues, such as reflecting the learning achievement.
\end{abstract}

Keywords-Innovative, e-therapy service, design of mobile application, higher education

\section{Introduction}

The emergence of cyber counselling has been widely spread throughout the world with a variety of instrumental basis in the extent of variety deriving from utilising the digital devices which may potentially refer to the virtual interaction. The expected outcome is that the approach design could help the client receive the more convenient and satisfactory services. Many studies have been conducted on cyber counselling in areas of psychology [1], social work ethics [2], the sport [3], mental health [4] and spiritual enhancement [5]. However, there has been less attention from the scholarly work to address the extent of therapy service in HE setting using mobile application. Delivering academic therapy services effectively in the way which can be transmitted across borderless space, proposing the framework model using mobile application design aims to help students handle their academic issues in receiving tips and advices for getting better in their learning success. 
This is usually conducted in the face to face setting where the students come to the lecturer's office to gain the academic advice and instruction recommended in planning the learning achievement in every semester. The challenge on the location where the students should face in providing the appropriate time and accurate place to receive the service should be considered in particular by promoting the model application. With this regard, the innovation to make the service conducted in borderless space plays a significant role in giving the shortcut mode with effective time and remote control. This initiative could make the service more flexible in solving the separate locations or from remote areas. Thus, the main initiative of this study is to present the framework model of mobile application design in therapy service in HE setting. Setting for the borderless area in delivering the communication and advice, the proposed design is supposed to transfer the counselling in better quality service between students and advisors.

\section{$2 \quad$ Literature Review}

\subsection{Significance of E-Therapy in Mobile Application Design}

With the proliferation of digital technology, cyber application has shown positive results which include faster and more effective communication process. Internet communication definitely saves time because lecturers are not expected to meet students face-to-face. For instance there are many benefits like smartphone for learning aid [6], adaptive teaching competencies in big data [7], adaptive technology skills: careful engagement in the digital information age [8] and also empowering learning culture as student identity construction in higher education context [9]. Also, information dissemination to students covers wider range than the existing traditional method. Cyber counselling offers a new opportunity for advisors and students to generate an active learning session outside the classroom. Using mobile technology showed positive improvements physical activity. The advantage of virtual learning made it easy for course coordinator to advise wider range of students as individual meeting has been found to be time consuming. Aside that, cyber counselling can reduces the overhead as a counsellor can cyber counsel multiple students at the same time. It also helps in terms of getting insight to the users' in form of additional experience and also number of information can be assessed directly from the sources [10].

In particular, the cyber counselling could offer a new opportunity for advisors and students to generate an active counselling session outside the classroom [11]. The benefits can also be enhanced seemingly to improve the positive counselling activity and the improvement to the individual students through the counselling service [12]. Furthermore, the benefit can also be visible with such proposed mobile course coordinator system using mobile phone in assisting the subject module of study amongst the students by keeping track of their courses anytime and anywhere [13]. Moreover, the contribution can also be viewed in innovative teaching to deliver the learning process with big data approach [14]. This initiative has been also transmitted into the mobile learning management system (LMS) [15]. In addition, LMS associated with 
online student academic achievements would enable in filling the students' need of learning [16]. In previous studies, proposed a mobile course coordinator system integrated and accessible on mobile phone. This was to aid students in choosing the necessary courses to undertake in their various fields of study. Similarly, students were able to keep track of their courses by using their cell phones, anytime and anywhere.

Recent technological advancement in wireless technology has made possible learning on the move. Educational stakeholders such as school administrators, teachers, and learning tool developers have encouraged the use of mobile learning management systems to cater to students' needs. Explained further the number of obvious potentials inherent in mobile technology can be viewed such as increasing patient adherence to medication, allowing therapists to monitor clients' progress, improving the therapeutic relationship, and providing information to both clients and therapists. Mobile learning existence can be used to improve education and facilitate student to easily access to the content regardless of their location. Another similar potential benefit can also be seen across mobile technology application which assisted to provide access to counselling in increasing patience's adherence to the medication rules and also to help them get counselling by making a control with monitoring students' progress improving the counselling relationship, and providing information to both students and advisor [17]. There is also an illustrated contribution to signify the particular essence using mobile learning existence to improve education and facilitate student to easily access the content regardless of their location [18].

\section{$3 \quad$ Method}

This study aims to present the framework model for e-therapy service in HE setting by using the mobile application design. With this regard, the framework with standard process is used to develop the pattern of delivering information and instruction role between client and advisor. In providing the process with the best quality output of transferring information, enhancing e-therapy service for the learning success requires the process with an inseparable link between communication and digital devices like mobile or smart phones. Establishing behavioural integrity and consistency in the academic planning should fulfil the necessary requirement between advisor and client. By using the mobile application design, e-therapy service in HE setting can be conducted in the separate location or borderless space. Elaborating the design of mobile application, enhancing academic counselling in the current procedure for etherapy service is commenced with delivering information on the schedule in exact date. The design of this initiative will be structured in arranging the therapy service session with determining the particular issues in the academic purpose in terms of strategies and difficulties in the learning success. In order to achieve this stage, there are several stages which can be carried out in the mobile application design. Those are analysing the instrumental basis, process and implementation stage. 


\section{$4 \quad$ Result And Discussion}

\subsection{Designing Instrumental Basis in the Logical Design for Mobile Application System}

Instrumental basis refers to the way to construct the pattern for the e-therapy service in HE setting in mobile application system. Providing the integration of data with documentation progress to monitoring further away, the rules of applying the schedule which is taken early between students and advisors is made into this mobile application design. As a result, both time commitment and schedule arrangement should be involved as an inextricable impact related to the e-therapy service in the way which can be transmitted to generate the counselling process. The particular basis refers to enhance the way of design to record the communication delivered from e-therapy service within facilitating the platform to gather the data in that process. The mechanism here is engaged into the counselling process in the way if no further consolidation made by the advisor, then the notification signal will alert to reconsider in transmitting the urgent response.

Analysing design illustration is regarded as an attempt to transform the requirement process with instrumental basis in the logical design as shown in the figure 1 below.

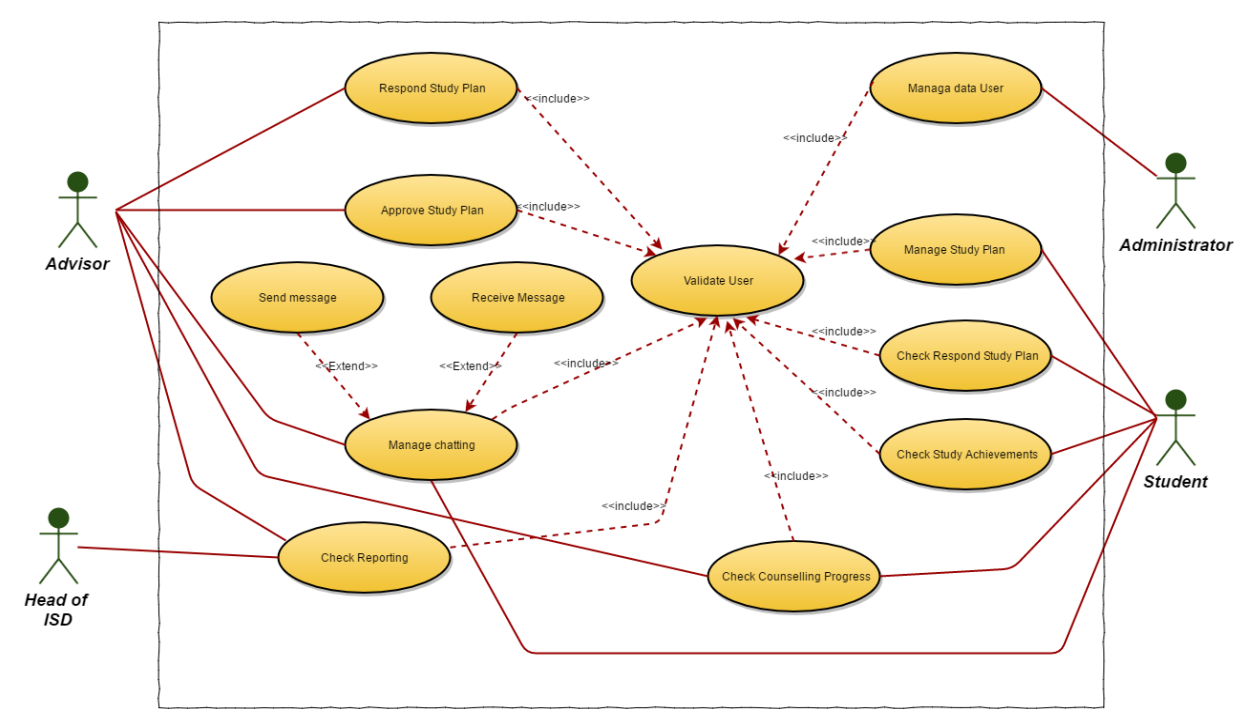

Fig. 1. Instrumental Basis in the Logical Design for Mobile Application System

This approach is used in the stage of logical design with the technique which is a graphic language for specifying, visualizing, constructing, and documenting information systems was used to implement in a variety of models with a specific extensions to expand the application. With such features, this instrumental basis refers to present a high level of generalization and extensions within the various types that can 
expand the application stage process. Elucidating the core stages to enhance the instrumental basis is dealt with the extent of representation which refers to the behaviour diagrams between the user and advisor. Describing the set of actions which some system should perform a sequence of actions, the different use cases are used to providing something in collaboration with one or more external users within the system. Providing the signal for identifying and modelling of the context has been widely exerted by observing what kind of certain level and stage of the problem domain. Drawn as a horizontal ellipse, the system requirements modelling would enhance the set of tasks generated with the system viewing the scope and elements into the impact to lead to use between user and system to enable them interact with.

Table 1. Description between user and roles

\begin{tabular}{|l|l|}
\hline User & Roles \\
\hline Advisor & Lecturers in the department as the academic advisor for students \\
\hline Student & Students in the department society \\
\hline Head of Department & Head of department Information system \\
\hline Administrator & Staff department who have responsible to managing the user data \\
\hline
\end{tabular}

Table 2. Description of use case

\begin{tabular}{|l|l|}
\hline Instrumental Basis & Description \\
\hline User validation process & To validate user on login process \\
\hline Managing user data & To manage import-export user data \\
\hline Managing plan for study & To provide student the optional of management study plan \\
\hline Checking the response for the study plan & To displaying advisor respond of academic study plan \\
\hline Checking the learning achievements & To displaying the study achievements have been passed \\
\hline Checking the progress & To displaying the progress \\
\hline Responding the study plan & To provide a tool for advisor to manage a respond for students \\
\hline Approving study plan & To provide a tool for advisor to approve learning plan \\
\hline Managing chatting & To manage the chatting included sending and receive message \\
\hline Checking the report & To display the reporting of academic \\
\hline
\end{tabular}

\subsection{Exploring Implementation Stage Process of E-Therapy Service in Mobile Application Design}

After dealing with the instrumental basis of e-therapy service in mobile application design, elucidating in detail on the way to implement it within the graphical visualization to describe dynamic aspects of the system is considered as a flow chart to represent the flow form in the workflows with stepwise activities and actions [19].To achieve this support for the option the activity can be described as an operation of the system generated with iteration and concurrency. In UML, an activity diagram is used to display the sequence of activities. Activity diagrams show the workflow from a start point to use such as in business process, in which this is utilised a process of computational and organizational activity. By facilitating the representation of the 
interaction flow indicated for the modelling of many decision paths in the progression of events with a high level of abstraction, activity diagrams of UML is conceived to provide situations in detail where the execution of some activities is using the parallel processing [20].

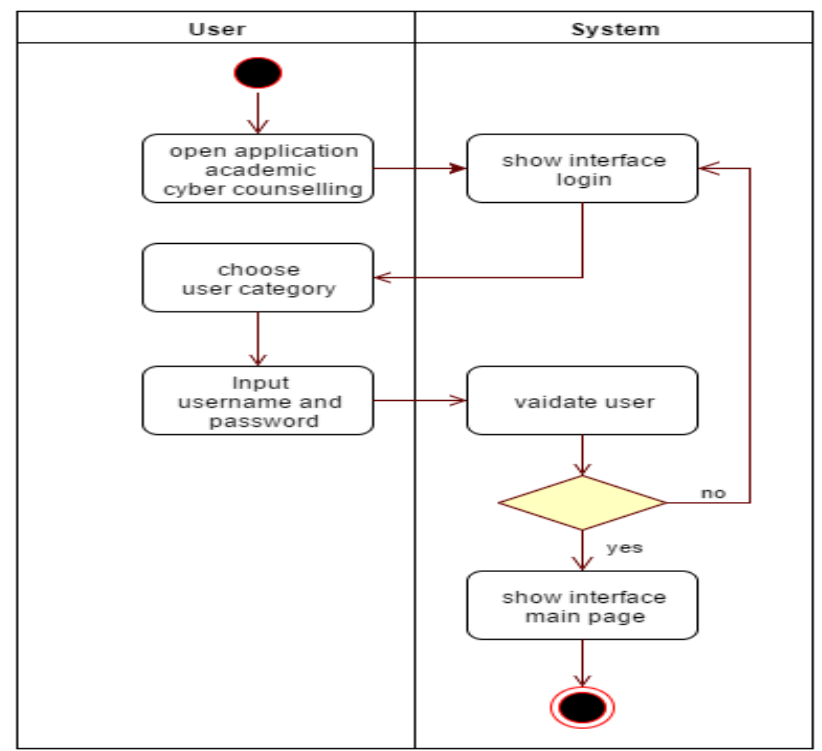

Fig. 2. Diagram process for validate user

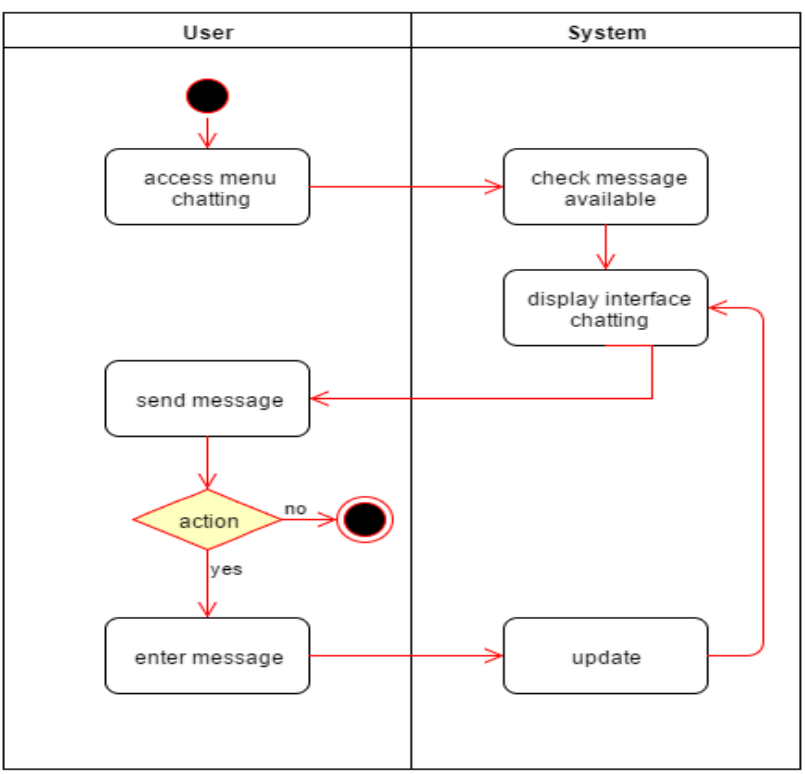

Fig. 3. Diagram design for managing the chatting 


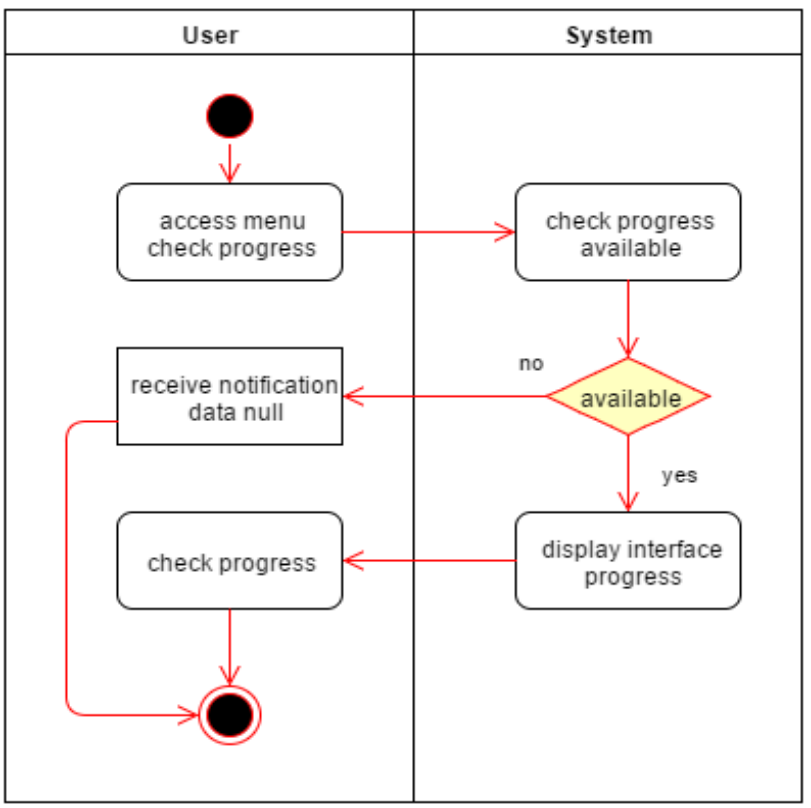

Fig. 4. Diagram process for checking the progress

The design application (see figure 2-4) illustrates the diagram process for validating the user, managing the chatting and checking the progress. The user needs to commence the system through opening application for academic cyber counselling. Moreover, by choosing the category, fulfilling the name and password to validate the user's information detail would lead to the next process in showing the interface main page. When getting finished, the user can start with chatting through accessing the menu. Checking message available as an attempt to display the interface chatting could be further transformed into sending the message, especially in delivering the communication to gain the update. In particular, managing the chatting in delivering therapy service may also be enhanced to see the progress where this stage is made by the advisor on the system available. By clicking the menu on 'progress', the user can easily see the further enhancement through receiving the alert notification made by the system automatically. With this regard, displaying interface progress here refers to the way which has two choices, yes or no. The code 'yes' here means that the system will deliver to the further process on progress side then transferring into the checking progress. However, when the decision 'no', then alert system may give the notification for the user to check the progress.

Based on figure 2 to figure 4 , can identify the system requirements such as:

1. The system should display user category for login authentication.

2. The system must verify the correcting user to login.

3. The system, after the menu selection by user should display the interface of Login, chatting, and progress. 
4. The system should provide the functional of send or receive message on managing chatting interface.

5. The system must provide the real time process to update database.

6. The system should provide the integration data for users

Sequence diagrams: Sequence diagrams are used to present the dynamic behaviour of system design while class diagrams are system static structure. As one of two kinds of UML interaction diagrams, a sequence diagram shows interactions between objects arranged in a time sequence [21].

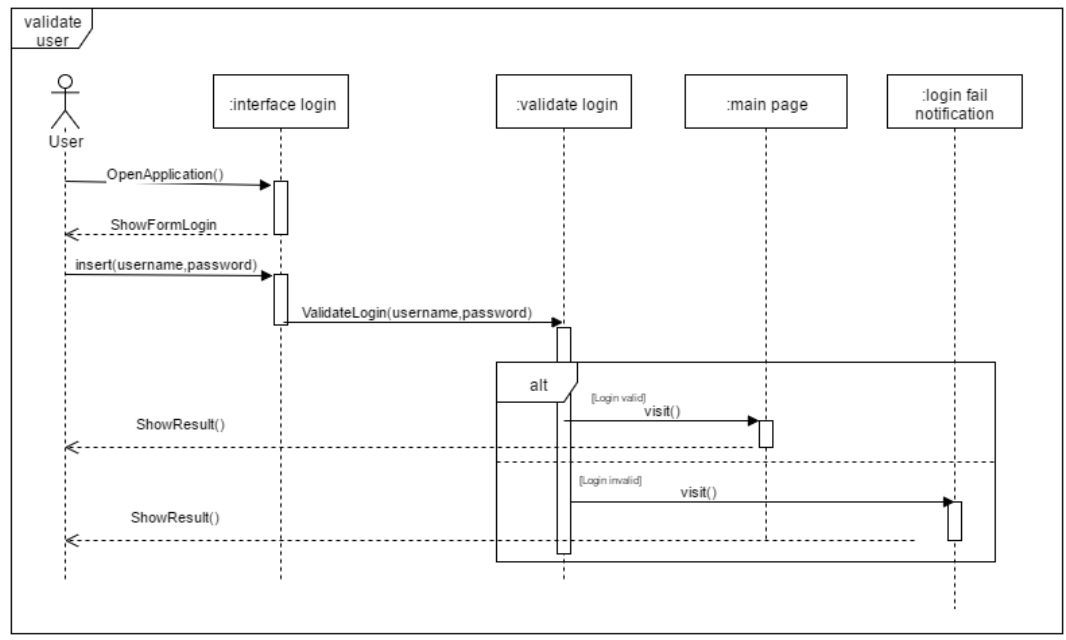

Fig. 5. Subsequent diagram for user validation

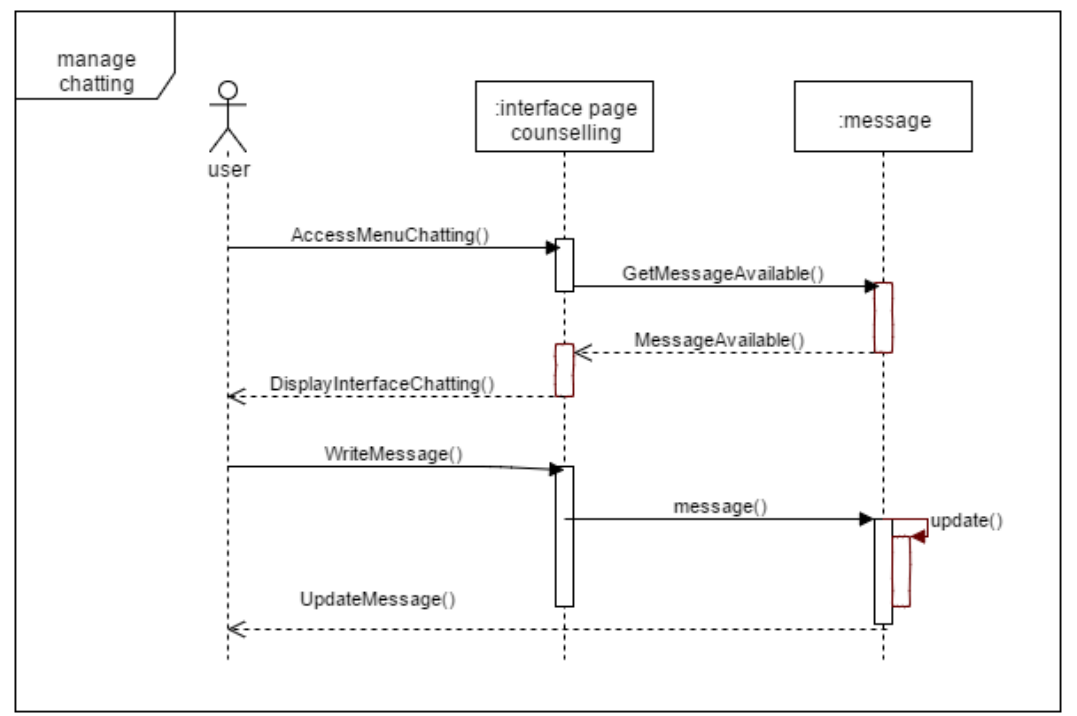

Fig. 6. Subsequent diagram for managing the chatting 


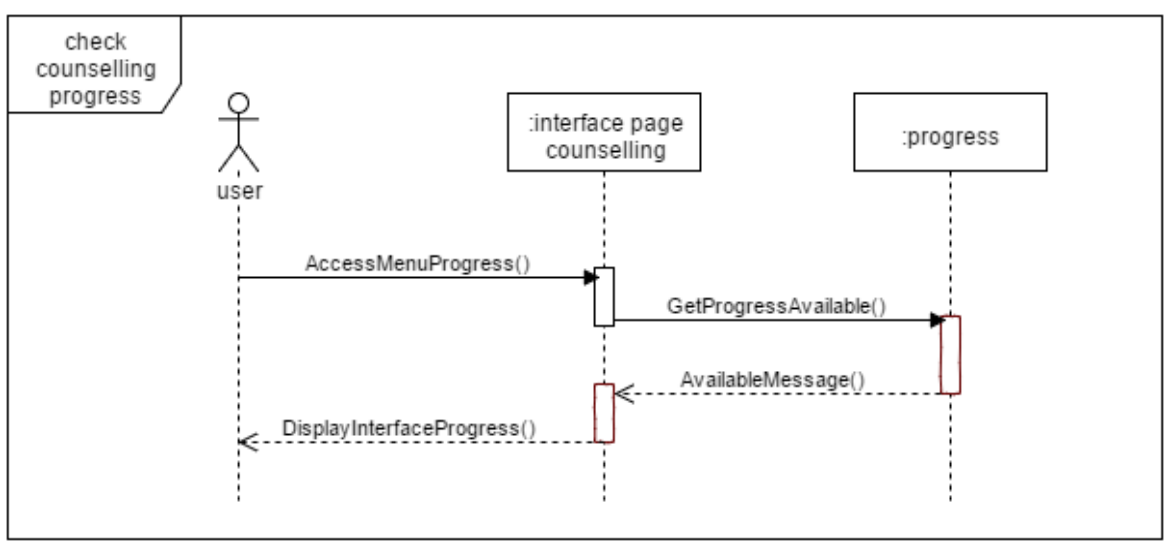

Fig. 7. Subsequent diagram for checking the progress

This stage as illustrated by the figure 5 . This process begins with validating the users by putting user name and password. The class Validate Login would be transformed into the authentication process. This can be enhanced through fitting the data from the input available on the database. If that valid, the process system would transfer directly to the page on main menu. This attainment would be also failed when login application unsuccessful.

Class diagram: Class diagram consists of various classes and relationships with each other. In its first portion, class diagram consist of its name, in the second portion it consists of attributes and in third it consists of operations. For the connection of class diagram, the relationship exists between the different classes. To represent the relationship between super class and subclass, the generalization relationship takes place in the static part of the UML model, UML class diagram exists to analyse the complexity of the software system [22]

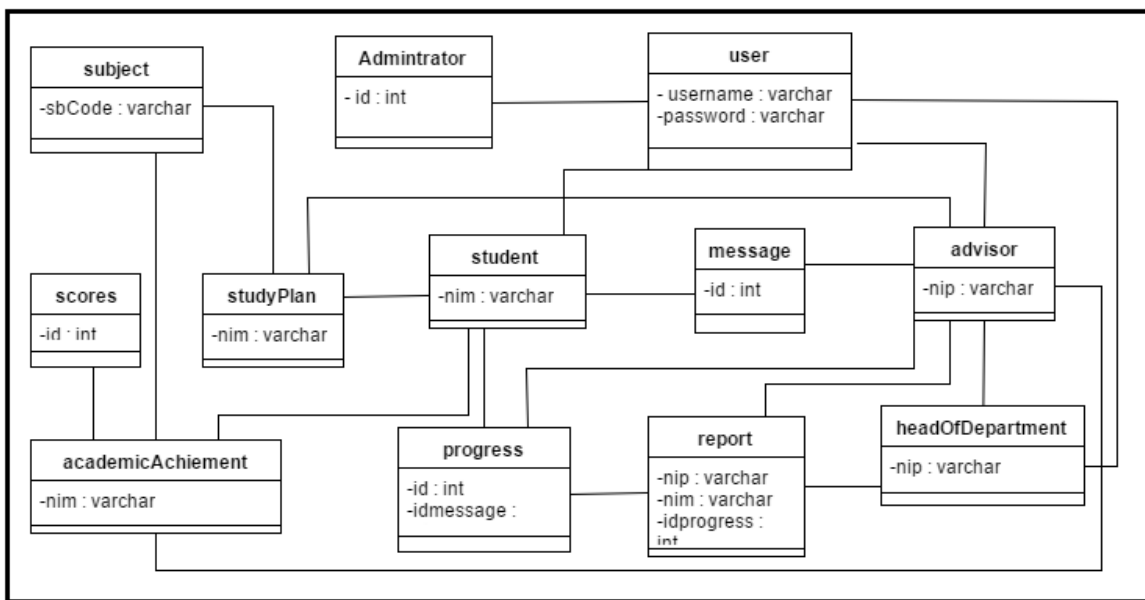

Fig. 8. Class diagram of proposed system 
Based on figure 8 , the process starts from the relation amongst the class illustrated in detail towards the use case diagram and sequence diagram. With regard to the system proposed above, there are three core users such student, advisor. In line with the subsequent process, the stage should be transformed into the study achievement stage where the users have chance to simultaneously relate to the procedural context to the head of department program. There is needed to further analyse the significance and effectiveness of this model framework in higher education (HE). The outstanding expectation will be achieved through developing the mobile application of academic cyber.

\section{Conclusion}

This paper did elaborate on the design of mobile application design for academic counselling. This is to promote the further analysis on the process would be transformed in the process of academic counselling. Designed in the context of higher education (HE), the outstanding expectation will be achieved through developing the mobile application of academic cyber counselling. This study will contribute to propose a design of academic cyber through mobile device where this aims to help students to solve their academic issues, such as reflecting the learning achievement. The proposed design would promote the improvement process held in HE. Moreover, the target focus is also to promote a better communication among students and advisors. The further investigation would be conducted to point out the process of implementation level to see how it can be generated seemingly in the academic counselling application system. In further, the subsequent study is to assess this application amongst the users in HE to see the effectiveness and significance of the proposed application system.

\section{References}

[1] Mishna, F., Levine, D., Bogo, M., \& Van Wert, M. (2013). Cyber Counselling: An Innovative Field Education Pilot Project. Social Work Education, 32(4), 484-492. https://doi.org/10.1080/02615479.2012.685066

[2] Mishna, F., Bogo, M., Root, J., \&Fantus, S. (2014). Here to stay: Cyber communication as a complement in social work practice. Families in Society: The Journal of Contemporary Social Services, 95(3), 179-186. https://doi.org/10.1606/1044-3894.2014.95.23

[3] Rivera-Rodriguez, A. J., Faye, H., Karsh, B. T., Carayon, P., Baker, C., \& Scanlon, M. C. (2012).A survey study of nursing contributions to medication management with special attention to health information technology. IIE Transactions on Healthcare Systems Engineering, 2(3), 202-210. https://doi.org/10.1080/19488300.2012.710296

[4] Mishna, F., Bogo, M., \& Sawyer, J. L. (2015). Cyber counseling: illuminating benefits and challenges. Clinical Social Work Journal, 43(2), 169-178. https://doi.org/10.1007/s10615013-0470-1

[5] Watson, N. J., \& Nesti, M. (2005). The role of spirituality in sport psychology consulting: An analysis and integrative review of literature. Journal of applied sport psychology, 17(3), 228-239. https://doi.org/10.1080/10413200591010102 
[6] Anshari, M., Almunawar, M. N., Shahrill, M., Wicaksono, D. K., \& Huda, M. (2017). Smartphones usage in the classrooms: Learning aid or interference?. Education and Information Technologies, 1-17. https://doi.org/10.1007/s10639-017-9572-7

[7] Huda, M., Shahrill, M., Maseleno, A., Jasmi, K. A., Mustari, I., \& and Basiron, B. (2017a). Exploring Adaptive Teaching Competencies in Big Data Era. International Journal of Emerging Technologies in Learning, 12(3), 68-83. https://doi.org/10.3991/ijet.v12i03.6434

[8] Huda, M., Jasmi, K. A., Hehsan, A., Shahrill, M., Mustari, M. I., Basiron, B., \& Gassama, S. K. (2017b). Empowering Children with Adaptive Technology Skills: Careful Engagement in the Digital Information Age. International Electronic Journal of Elementary Education, 9(3), 693-708.

[9] Huda, M., Sabani, N., Shahrill, M., Jasmi, K. A., Basiron, B., \& Mustari, M. I. (2017c). Empowering Learning Culture as Student Identity Construction in Higher Education. Student Culture and Identity in Higher Education, 160-179.

[10] Miftah, M. (2013). Reformulating the role of educators in ict era. Indonesian Journal of Early Childhood 2(1), 13-19.

[11] Blissenden, M., Clarke, S., \& Strevens, C. (2012). Developing online legal communities. International Journal of Law and Management, 54(2), 153-164. https://doi.org/10.1108/ 17542431211208568

[12] Verwey, R., Van der Weegen, S., Spreeuwenberg, M., Tange, H., Van der Weijden, T., \& De Witte, L. (2016). Process evaluation of physical activity counselling with and without the use of mobile technology: A mixed methods study. International journal of nursing studies, 53, 3-16. https://doi.org/10.1016/j.ijnurstu.2015.10.008

[13] Lee, Y., Cho, J., Jeong, S., Han, S., \& Choi, B.-U. (2011). A Mobile Course Coordinator System. LNCS, 6537, 185-194. https://doi.org/10.1007/978-3-642-20539-2 21

[14] Huda, M., Anshari, M., Almunawar, M. N., Shahrill, M., Tan, A., Jaidin, J. H., \& Masri, M. (2016). Innovative Teaching in Higher Education: The Big Data Approach. The Turkish Online Journal of Educational Technology, 15(Special issue), 1210-1216.

[15] Anshari, M., Alas, Y., Hamid, M. H. S. A., \& Smith, M. (2016). Learning Management System 2.0: Higher Education. Handbook of Research on Engaging Digital Natives in Higher Education Settings, 265-279. Penynselvenia, US: IGI Global. https://doi.org/10.4018/978-1-5225-0039-1.ch012

[16] Han, I., \& Shin, W. S. (2016).The use of a mobile learning management system and academic achievement of online students. Computers \& Education, 102, 79-89. https://doi.org/10.1016/j.compedu.2016.07.003

[17] Norris, L., Swartz, L., \& Tomlinson, M. (2013). Mobile phone technology for improved mental health care in South Africa: possibilities and challenges. South African Journal of Psychology, 43(3), 379-388. https://doi.org/10.1177/0081246313493376

[18] Almatari, A. Y., Iahad, N. A., \& Balaid, A. S. (2013). Factors influencing students' intention to use mlearning. Journal of Information Systems Research and Innovation (JISRII), 5.

[19] Bastos, R. M., \& Ruiz, D. D. A. (2002, January).Extending UML activity diagram for workflow modeling in production systems.In System Sciences, 2002.HICSS. Proceedings of the 35th Annual Hawaii International Conference on (pp. 3786-3795). IEEE. https://doi.org/10.1109/hicss.2002.994510

[20] Santos, P. M., de Melo Braga, M., \& José Rover, A. (2013). Eliciting intrinsic knowledge in the business processes of electronic government with UML extensions. Business Process Management Journal, 19(2), 318-335. https://doi.org/10.1108/1463715 $\underline{1311308330}$ 
Paper-Innovative E-Therapy Service in Higher Education: Mobile Application Design

[21] Li, X., Liu, Z., \& Jifeng, H. (2004). A formal semantics of UML sequence diagram. 2004 Australian Software Engineering Conference. Proceedings., 168-177.

[22] Shakil, S., \& Hazela, B. (2016). Formalization of UML Class Diagram. International Journal of Engineering Science and Computing, 6251.

\section{$7 \quad$ Authors}

Miftachul Huda*, Kamarul Azmi Jasmi, Mohd Ismail Mustari, Bushrah Basiron, Ahmad Kilani Mohamed, Wan Hassan Wan Embong, and Jimaain Safar are with Universiti Teknologi Malaysia, UTM Skudai, 81310 Johor, Malaysia (halimelhuda@gmail.com).

Article submitted 06 February 2017. Published as resubmitted by the authors 23 March 2017. 